\title{
Biologando sobre Saúde no Contexto da Pandemia da COVID-19 via Plataforma de Videoconferência
}

\author{
Rayane de T. M. Ribeiro ${ }^{1}$, Lydia D. M. Pantoja ${ }^{1}$, Germana C. Paixão ${ }^{1}$ \\ ${ }^{1}$ Curso de Ciências Biológicas EAD/UAB - Universidade Estadual do Ceará \\ (UECE/UAB), Av. Dr. Silas Munguba 1700, Itaperi, 60714-903 - Fortaleza - CE - \\ Brasil \\ rayane.tasso@uece.br, lydia.pantoja@uece.br, germana.paixao@uece.br
}

\begin{abstract}
In the context of the COVID-19 Pandemic, Distance Education gains even more evidence. In a reality of social detachment, the aim of this study is to evaluate the use of the Google meet application in a virtual lecture offered to Biological Sciences classes the distance to several cities in Ceará, Brazil. As a result, $100 \%$ of the students considered (totally or partially) the experience of the lecture to be satisfactory, in addition to the sound and image quality. The students made positive comments on the theme of the lecture and the researcher, in addition, also highlighted the timeliness of the discussion of COVID-19 and the importance of the lecture with reliable information in a context of dissemination of Fake News.
\end{abstract}

Resumo. No contexto da Pandemia da COVID-19, a Educação a Distância ganha ainda mais evidência. Em uma realidade de distanciamento social, o objetivo desse trabalho é avaliar a utilização do aplicativo Google meet em uma palestra virtual oferecida a turmas de Ciências Biológicas a distância de diversas cidades do Ceará, Brasil. Como resultados, $100 \%$ dos alunos consideraram (total ou parcialmente) a experiência satisfatória, além da qualidade de som e imagem. Os estudantes realizaram comentários positivos sobre a temática da palestra e o pesquisador, além disso, ressaltaram, ainda, a atualidade da discussão da COVID-19 e a importância da palestra com informações confiáveis em um contexto de disseminação de Fake News.

\section{Introdução}

A Educação a Distância $(\mathrm{EaD})$ é uma modalidade de ensino intrisecamente relacionada as novas tecnologias da informação e comunicação (TIC) [Churkin 2020]. A EaD, portanto, está consolidada no Brasil e sob constante transformação com a incorporação de novas ferramentas de comunicação. $O$ aprendizado nessa modalidade pode ser bidirecional, síncrono, assíncrono e massificado para regiões distantes geograficamente e de diferentes níveis sócio-econômicos [Conde et al. 2017; Ribeiro et al. 2018; Churkin 2020].

Apesar de estar bem difundida no país, a $\mathrm{EaD}$ ainda enfrenta críticas e preconceitos. O principal questionamento é que essa modalidade prescindiria a interação pessoal entre professor e aluno, além do espaço da sala de aula. Cabe ressaltar, no entanto, que o termo "a distância" não implica está atrelado obrigatoriamente à falta de interação entre professores e alunos [Oliveira e Dos Santos 2020]. 
Pelo contrário, professores e alunos podem estar em localidades distintas, mas interagirem sincronicamente mediados por diferentes ferramentas, como chat, videoconferência, dentre outras [Vilaça 2010; Brito et al. 2019].

Essa possibilidade de interação através da $\mathrm{EaD}$ com a utilização de diferentes TICs vem sendo comprovada no contexto da Pandemia da COVID-19. Todo sistema educacional foi remodelado e incorporou um conjunto de TICs para viabilizar o aprendizado dos estudantes em isolamento social em todo o mundo.

O Fundo das Nações Unidas para a Infância (UNICEF) destaca que é vital que os alunos continuem seu aprendizado de casa, utilizando todos os canais possíveis, rádio, televisão, internet e telefones celulares [UNICEF 2020]. Nesse contexto, as ferramentas de videoconferência viabilizam o ensino e a continuidade do aprendizado, além da discussão e conscientização dos estudantes com relação ao SARS-CoV-2, vírus causador da COVID-19 [Churkin 2020; Santos Júnior e Monteiro 2020].

Segundo Santos Júnior e Monteiro (2020), nesse momento de adaptação do processo de ensino-aprendizagem, os aplicativos de videoconferências constituem um recurso síncrono eficaz para interação a distância e com grandes potencialidades pedagógicas.

Assim, diante do cenário da COVID-19 e no âmbito de um curso de Educação a Distância, o objetivo desse trabalho foi avaliar a utilização do aplicativo Google meet em uma palestra virtual oferecida a turmas de Licenciatura em Ciências Biológicas a distância da Universidade Estadual do Ceará de diversas cidades do Ceará, Brasil. A palestra virtual versou sobre procedimentos técnicos da pesquisa, éticos e trajetória do pesquisador em saúde e como pontos centrais o conhecimento sobre doenças como câncer e a COVID-19, essa última a mais discutida com informações sobre o agente etiológico, formas de transmissão, prevenção e fontes confiáveis para obtenção de informações sobre a pandemia.

\section{Metodologia}

$\mathrm{Na}$ presente pesquisa foi avaliada a percepção geral de alunos $(n=76)$ sobre uma palestra virtual intitulada "Pesquisa em Saúde em tempos de pandemia" realizada no âmbito do curso de Ciências Biológicas a distância da Universidade Estadual do Ceará, BioEaD-UECE/UAB realizada através da plataforma de videoconferência Google meet (https://meet.google.com/).

O aplicativo Google meet foi escolhido, em virtude, da disponibilidade da plataforma do $G$ suite pela Universidade Estadual do Ceará. Além disso, o conjunto de professores, tutores e alunos do curso possuem familiaridade com o aplicativo, bem como por comportar até 250 alunos.

\subsection{Tipologia da pesquisa e construção do instrumento de coleta de dados}

No tocante a tipologia, este estudo configura-se como uma pesquisa quantiqualitativa aplicada, descritiva e survey, segundo Babbie (1999), Gerhardt e Silveira (2009) e Silva (2014).

Os dados foram coletados por meio de um questionário semi-estruturado misto com 13 questões, confeccionado através do aplicativo Google Forms (https://www.google.com/forms/about/), que foi avaliado em uma perspectiva quali- 
quantitativa. O questionário dividia-se em dois blocos: bloco 1 - caracterização sociodemográfica dos participantes com seis questões, para identificar aspectos pessoais dos alunos; bloco 2 - avaliação da palestra com sete questões; a fim de identificar a percepção quanto a aspectos técnicos e do conteúdo da palestra. A participação na pesquisa foi consentida por todos os alunos através de anuência em Termo de Consentimento Livre e Esclarecido (TCLE) enviado juntamente com o questionário. Cabe ressaltar, que foram observados e obedecidos todos os princípios éticos previstos na resolução CNS nº 510/2016.

Dentro da nossa proposta, a aplicação de questionário semi-estruturado misto mostra-se uma metodologia vantajosa, pois contemplou questões objetivas e subjetivas, uniformidade, obtenção de respostas mais rápidas e precisas, tempo considerável para resposta, sem custos, como discutido por Gerhardt e Silveira (2009) adaptado apud Santos (s.d.).

\subsection{Divulgação entre o público-alvo e palestra virtual via Google meet}

A palestra alvo foi divulgada entre o público-alvo (discentes da BioEaD-UECE) por meio de material de divulgação (folder e vídeos) publicados em redes sociais (Facebook e Instagram), por meio de e-mail institucional e grupos em aplicativo de mensagens (Whastapp) que incluiam o título da palestra, informações do palestrante, data, horário e link para acesso a sala de videoconferência.

A palestra virtual intitulada "Pesquisa em Saúde em tempos de pandemia" ocorreu no dia 19 de maio de 2020 e apresentou duração aproximada de 2 horas, sendo 1h 20 min para apresentação do tema pelo palestrante e 30-40 min para questionamentos dos discentes. Na palestra em questão foram discutidos a trajetória acadêmica do pesquisador, pesquisas em saúde relacionadas ao câncer e a pandemia da COVID-19 (Figura 1).

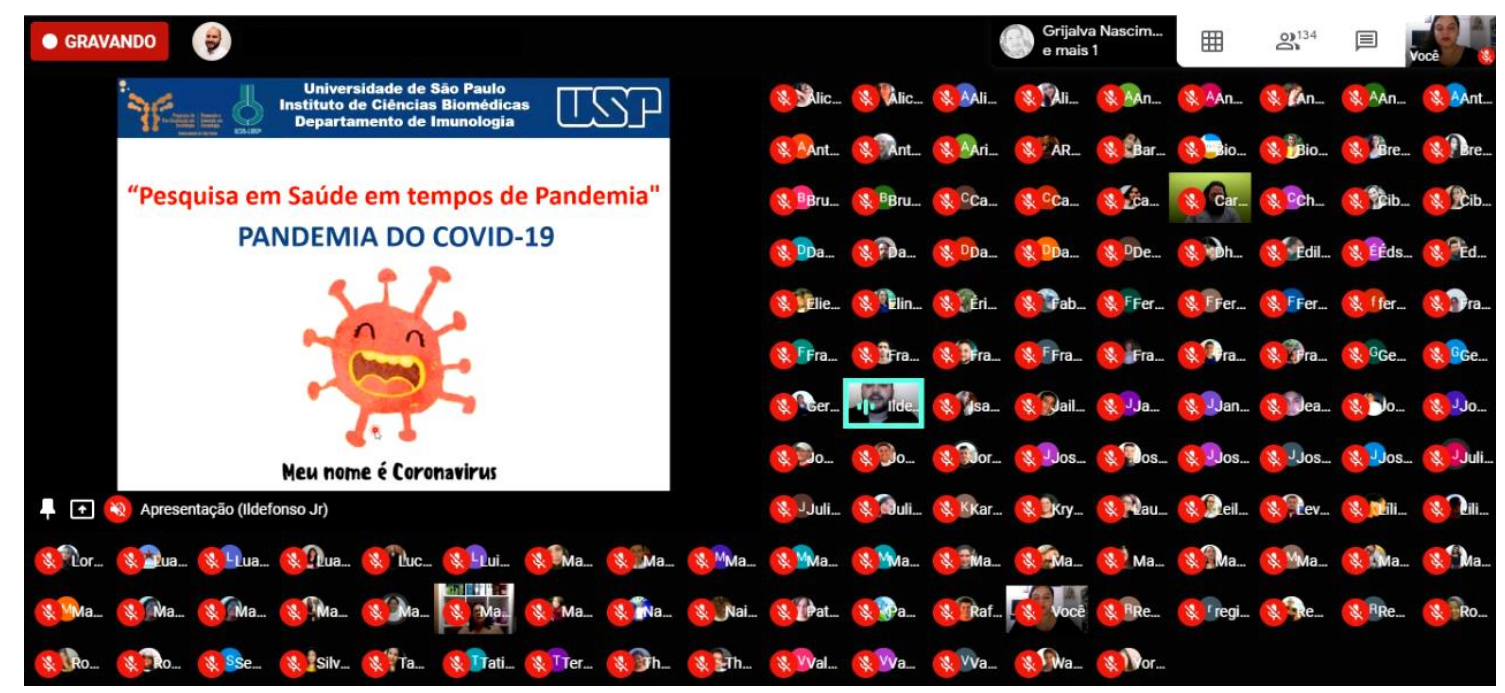

Figura 1. Imagem da palestra virtual "Pesquisa em Saúde em tempos de pandemia" realizada através do aplicativo Google meet.

\subsection{Obtenção e representação gráfica dos dados}

Os dados obtidos com a aplicação do questionário foram devidamente compilados e plotados em planilhas do aplicativo Microsoft Office Excel 2007. Com 
base nos dados da questão subjetiva que solicitava aos alunos a inclusão de, no mínimo, três palavras-chave sobre a palestra, foi produzida uma nuvem de palavra por meio do sítio Word Clouds (https://www.wordclouds.com/). A representação gráfica dos dados foi realizada por meio de tabela e nuvem de palavras, essa última é uma representação gráfica na qual o tamanho da palavra é proporcional à sua frequência no texto, indicando quais delas foram consideradas significativas e remetem diretamente aos assuntos abordados na palestra virtual.

\section{Resultado e discussão}

\subsection{Caracterização sociodemográfica do público-alvo}

A tabela 01 apresenta a caracterização geral do perfil dos alunos entrevistados, abrange aspectos sociodemográficos, tais como: idade, sexo, estado civil, com quem residem e em quantas pessoas, além de filhos e número de filhos, caso possuam.

Tabela 1. Aspectos sociodemográficos dos alunos entrevistados

\begin{tabular}{|c|c|c|}
\hline VARIÁVEL & FREQ. & $\%$ \\
\hline \multicolumn{3}{|l|}{ 1. Sexo } \\
\hline Feminino & 50 & $65.8 \%$ \\
\hline Masculino & 25 & $32.9 \%$ \\
\hline Não informado & 1 & $1.31 \%$ \\
\hline \multicolumn{3}{|l|}{ 2. Idade (anos) } \\
\hline 17 a 25 & 22 & $29 \%$ \\
\hline 26 a 35 & 35 & $46 \%$ \\
\hline Acima de 35 & 19 & $25 \%$ \\
\hline \multicolumn{3}{|l|}{ 3. Estado Civil } \\
\hline Solteiro(a) & 38 & $50 \%$ \\
\hline Casado(a)/União Estável & 35 & $46 \%$ \\
\hline Divorciado(a) ou Viúvo(a) & 3 & $4 \%$ \\
\hline \multicolumn{3}{|l|}{ 4. Com quem reside? } \\
\hline Amigos (as) & 0 & $0 \%$ \\
\hline Esposa + marido e/ou esposa + marido e filhos & 38 & $50 \%$ \\
\hline Namorado / namorada & 2 & $2.6 \%$ \\
\hline Pais e/ou irmãos & 26 & $34.2 \%$ \\
\hline Parente(s) & 7 & $9.2 \%$ \\
\hline Sozinho(a) & 3 & $4 \%$ \\
\hline \multicolumn{3}{|l|}{ 5. Número de pessoas que residem em sua casa } \\
\hline $1-2$ & 17 & $22.4 \%$ \\
\hline 3-5 & 53 & $69.7 \%$ \\
\hline 5 ou mais & 4 & $5.3 \%$ \\
\hline \multicolumn{3}{|l|}{ 6. Tem filhos? } \\
\hline Sim & 35 & $46 \%$ \\
\hline Não & 41 & $54 \%$ \\
\hline \multicolumn{3}{|l|}{ Caso sim, qual o número de filhos? } \\
\hline $1-2$ & 29 & $82.9 \%$ \\
\hline $3-4$ & 6 & $17.1 \%$ \\
\hline 5 ou mais & 0 & 0 \\
\hline
\end{tabular}

FREQ: frequência; \%: porcentagem

Com base na tabela 1, perecebe-se que a maioria dos discentes do curso é do sexo feminino (65.8\%), esses resultados são similares aos obtidos por ABED (2010), Luz (2013) e Ribeiro et al. (2018). Os referidos autores ressaltam que as mulheres são a maioria em cursos de graduação a distância. Isso decorre, principalmente, da maior 
flexibilidade de horários nessa modalidade que permite a mulher trabalhar, cuidar dos filhos e afazeres domésticos; além do menor investimento financeiro e por contemplar regiões mais distantes dos centros urbanos [Paixão et al. 2016; Albino et al. 2020].

Quanto a faixa etária, a maioria dos estudantes, apresenta de 26 a 35 anos predomina com 46\%. Segundo Tamariz e Souza (2015), os alunos da Educação a distância concentram-se, especialmente, na faixa dos 21 a 40 anos no Brasil.

Com relação ao estado civil, em geral, os estudantes são solteiros (50\%). No entanto, o número de alunos casados ou em união estável também é expressivo, contemplando $46 \%$ dos entrevistados. A maioria dos entrevistados, $50 \%$ residem com cônjuge ou cônjuge e filhos. Cabe ressaltar, ainda, os $34.2 \%$ que afirmam residir com pais e/ou irmãos. Levando em consideração também, o número de pessoas na residência, $70 \%$ dos discentes coabitam com 3 a 5 pessoas em suas unidades familiares. Dessa forma, os estudantes de EaD precisam conciliar seus estudos com uma rotina familiar, bem como disponibilizar tempo pra cônjuges, filhos, pais ou demais residentes da sua casa. Com isso, esse perfil de aluno encontra nessa modalidade uma forma de conciliar estudos, família e trabalho [Ribeiro et al. 2018].

\subsection{Biologando através do vídeo: percepções gerais sobre a palestra virtual}

As palestras virtuais oferecidas pela BioEaD constituem, na perspectiva do núcleo gestor estruturante (coordenação e equipe de tutores), uma proposta de interação com os alunos do curso através do aplicativo Google meet (ferramenta síncrona). Os resultados encontrados demonstram que quanto a eficácia da divulgação da palestra, os discentes consideraram que a palestra foi bem divulgada com $68(89.5 \%)$ assinalando "concordo totalmente" e oito (10.5\%) "concordo parcialmente". Em relação a proposta de interação e discussão de aspectos da pesquisa em saúde em tempos de pandemia através do aplicativo Google meet com pesquisador externo, corpo de professores e tutores da BioEaD e os discentes; 68 alunos (89.5\%) indicaram que se adaptaram totalmente ao formato da palestra considerando-a uma experiência satisfatória, enquanto oito $(10.5 \%)$ afirmaram que parcialmente.

Segundo Santos Junior e Monteiro (2020), em análise do aplicativo de videoconferência Zoom, enfatiza que a utilização de aplicativos de teleconferência consiste em uma opção para oportunizar o aprendizado de forma flexível e remota. Além disso, a utilização desses aplicativos permitem a continuidade do processo educacional ou o aprendizado de novos saberes, reduzindo, ainda, os prejuízos

formativos decorrentes do isolamento social [Santos Junior e Monteiro 2020; Xavier et al., 2020].

Os aspectos relacionados a qualidade de som e imagem durante a palestra foram considerados adequados pelos $76(100 \%)$ alunos entrevistados; desses "adequado totalmente" por 62 alunos (81.6\%) e "adequado parcialmente" entre 14 alunos (18.4\%), respectivamente.

\subsection{Os caminhos do pesquisador sob a ótica dos alunos}

Em um momento inicial, o palestrante trouxe informações sobre sua trajetória acadêmica. Nesse sentido, os alunos foram indagados sobre a trajetória acadêmica do mesmo e se eles já tinham tido um conhecimento prévio sobre a vida de algum pesquisador. Dentre os alunos entrevistados, 42 (55.3\%) fizeram comentários 
extremamente positivos sobre a vida do pesquisador e a pesquisa por ele realizada, como por exemplo:

- "A palestra foi ótima, vai somar bastante na minha carreira acadêmica e ainda vou poder esclarecer algumas dúvidas das pessoas sobre o Covid-19."

- "Já tive experiência com outros pesquisador. Porém o atual é muito íntegro e tem uma grande capacidade. Fiquei orgulhoso em ter participado desta satisfeito."

- "Me senti inspirada para seguir o mesmo caminho."

- "Quero ser pesquisadora como ele."

— "Sim. Átila Iamarino, microbiologista."

Observa-se através das falas dos alunos que a palestra representou um ponto de reafirmação da Ciência como uma atividade essencial para a vida humana e percebida pelos discentes como tal. Além disso, os alunos ressaltam a complexidade do "fazer Ciência", mas sentem-se instigados a buscar uma carreira acadêmico-científica. O papel da Ciência, por exemplo, na promoção da saúde; é percebido pelos estudantes que, ainda, mencionam cientistas que trabalham com divulgação como o microbiologista “Átila Iamarino". Segundo Arthury e Garcia (2020), esses pontos são importantes para uma conscientização sobre a importância da Ciência sob uma perspectiva Kuhniana e auxiliar no combate a movimentos anti-científicos, como anti-vacina e terraplanismo, baseados em notícias falsas (Fake News).

Outros 34 (44.7\%) estudantes declararam que nunca tinham tido contato ou conhecimento sobre como é a vida de um pesquisador, mas também ressaltaram a importância da palestra e o aprendizado obtido através dessa interação. Como pode ser verificado nas falas de alguns desses alunos abaixo:

- "Não tinha conhecimento, sobre a pesquisa muito desafiadora mas muito satisfatório."

— "Não. Me despertou mais interesse pela área acadêmica."

- "Não, foi o máximo, foi uma experiência única ter uma pessoa que está cuidando (Estudando, elaborando) tão de pertinho da doença que afeta o mundo inteiro."

A possibilidade de interagir e descobrir mais fatos sobre um tema de grande repercussão com informações confiáveis cientificamente foram apontamentos recorrentes dos discentes durante o chat do Google meet e nas demais falas dos estudantes, aqui não incluídas. A aproximação dos estudantes com o pesquisador ajudou-os a ampliar seu entendimento da trajetória, desafios e contribuições de um cientista. Essa interação é um dos pontos preconizados por Chassot (2003) com a ideia de alfabetização científica e a formação de cidadãos científica e socialmente críticos.

\subsection{Saúde em discussão: câncer e a Pandemia da COVID-19}

Sobre o conteúdo da palestra, é possível dividir as declarações dos estudantes em dois conjuntos de comentários, o primeiro relacionado estritamente a aspectos das doenças discutidas (câncer e COVID-19), incluindo características, detecção, prevenção e técnicas biológicas para combate dessas doenças; e o segundo relativo ao palestrante, como conduta ética do pesquisador e domínio dos assuntos. 
Com relação ao especificamente as doenças (câncer e COVID-19), 49 (64.5\%) alunos em seus comentários trouxeram temas, como: informações sobre o câncer relacionado à regeneração, receptor PAF e diferentes terapias; já da Covid-19, dados que incluem caracterização do vírus SARS-CoV2, métodos de prevenção e tratamento e potencial vacina produzida em Oxford. Além disso, os alunos ressaltaram a atualidade da discussão com informações confiáveis sobre a COVID-19, em um contexto de disseminação de notícias falsas, conhecidas por "Fake News".

No contexto da pandemia da COVID-19, seria esperado que as informações acerca dessa doença viral que paralisou diversos segmentos da sociedade atrairiam maior atenção dos estudantes, como evidenciado na Figura 2. Segundo Sousa Júnior et al. (2020), o mundo, em especial os governantes e gestores públicos de saúde, está buscando evitar à propagação do novo coronavírus, o SARS-CoV-2, causador da COVID-19. O autor reforça a importância do compartilhamento de informações confiáveis para o controle do SARS-CoV-2, conforme os preceitos da denominada educação para saúde. Durante a palestra e, dentre as palavras-chave indicadas, os alunos mencionam a "conscientização", "compreensão", "experimentos", "pública" e "qualidade", que remetem a essa necessidade de informação de fácil compreensão baseada em experimentos científicos, pública e de qualidade. Ressaltamos, também, o interesse dos alunos em pesquisas oncológicas que foram consideravelmente citadas pelos estudantes.

O outro conjunto de alunos, totalizando 27 (35.5\%) dos entrevistados, focou seus comentários na conduta e explanação do palestrante. Dentre as observações, destacam-se a didática, clareza e domínio do conteúdo, além da conduta ética nas pesquisas apresentadas.

A imagem de cientista trazida pelo pesquisador externo e percebida pelos estudantes foi positiva. Essa postura de cientista é interessante, também, dentro da concepção de uma alfabetização científica de Chassot (2003). Segundo Mesquisa e Soares (2008) ainda permanece uma imagem estereotipada do pesquisador e da Ciência, em especial no âmbito da mídia, o que ainda gera certa dificuldade na aprendizagem da Ciência pelos estudantes.

Além dos comentários, os discentes incluíram um total de 227 palavras que consideraram centrais durante a realização da palestra virtual. Dentre essas as palavraschave que apresentaram maior freqüência, portanto, mais mencionadas foram Covid-19 (23 menções), Câncer (18 menções), pesquisa (15 menções), radioterapia (8 menções), cloroquina e vacina ( 7 menções cada). Todas as palavras indicadas pelos alunos foram compiladas e são apresentadas através da uma nuvem de palavras abaixo (Figura 2). 


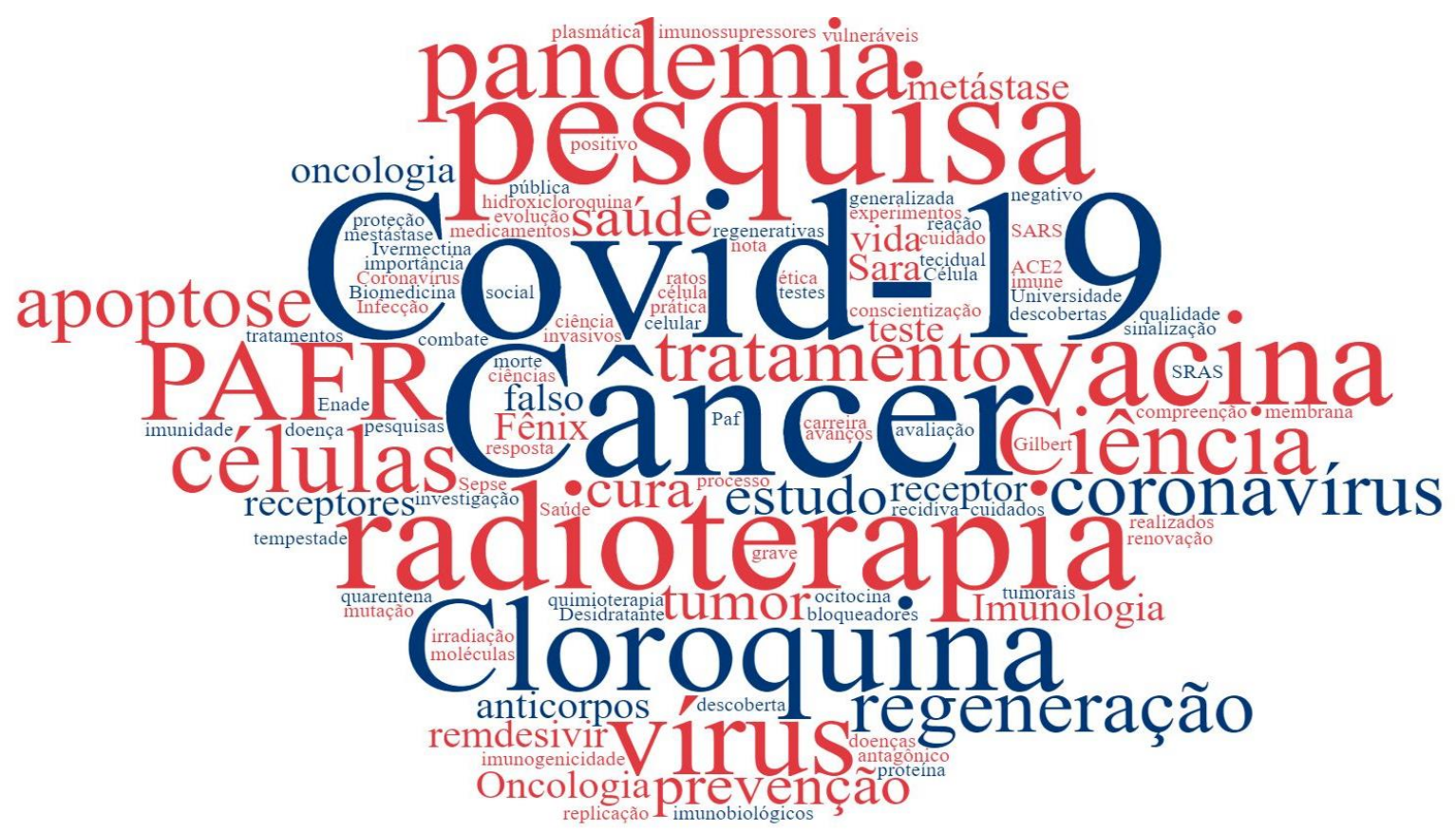

Figura 2. Nuvem de palavras gerada com as palavras-chave mencionadas pelos alunos em questionário semi-estruturado.

Diversos autores na literatura científica (Arruda 2020; Pimentel et al. 2020; Santos Júnior e Monteiro 2020) estão discutindo a influência da pandemia no aprendizado e a apontam que a utilização de diferentes recursos virtuais pode auxiliar na minimização dos efeitos da pandemia.

\section{Conclusões}

A utilização de ferramentas síncronas em um curso a distância permitiu uma maior interação com os discentes e, em especifíco, a utilização do Google meet para palestra virtual mostrou-se eficaz e elemento de motivação para os estudantes. Cabe ressaltar também, a aproximação dos estudantes com a realidade da pesquisa em Saúde e da vida de um pesquisador no exterior. Os alunos puderam interagir com o cientista e demonstraram compreender as demandas e rotina da pesquisa científica, além da ética e rigor com que a Ciência é desenvolvida.

Nesse sentido, a Ciência é vista pelos alunos como balizador de decisões pela sociedade, em especial para o enfrentamento da pandemia da COVID-19. Além disso, os estudantes reportaram a necessidade de que a Ciência seja permanentemente divulgada para evitarmos a disseminação de notícias falsas (Fake news).

\section{Referências}

Albino, J. P., Azevedo, M. L., Bittencourt, P. A. S. A evolução do EAD no ensino superior e suas tendências na educação Brasileira. Brazilian Journal of Development, Curitiba, 6 28146-28155, http://www.brazilianjournals.com/index.php/BRJD/article/view/10148/8493. Acesso em: 04 jun. 2020.

Arruda, E. P. (2020). Educação remota emergencial: elementos para políticas públicas na educação brasileira em tempos de Covid-19. EmRede, 7 (1), 257-275, 
https://www.aunirede.org.br/revista/index.php/emrede/article/view/621. Acesso em: 04 jun. 2020.

Arthury, L. H. M. and Garcia, J. O. (2020). Em Prol do Realismo Científico no Ensino. Ciência \& Educação, Bauru, 26, e20011.

ASSOCIAÇÃO BRASILEIRA DE EDUCAÇÃO A DISTÂNCIA - ABED. (2010). Censo EAD.br. Relatório analítico da aprendizagem a distância no Brasil. São Paulo: Pearson Education do Brasil.

Babbie, E. (1999). Métodos de pesquisas de Survey/Earl Babbie. Belo Horizonte: Editora UFMG.

Churkin, O. M. (2020). Educação à distância um marco civilizatório, um olhar holístico da pedagogia: sinergia e reflexões na conectividade em tempos de COVID-19. Brazilian Journal of health Review, 3 (2), 3178-3196.

Conde, I. B., Pantoja, L. D. M., Paixão, G. C., Arruda Filho, J. N. (2017). Dificuldades iniciais do ensino a distância na percepção dos alunos do curso de ciências biológicas em uma instituição pública de ensino superior no Ceará. In: Práticas de Inovação no Ensino Superior: a EaD nas Universidades Estaduais e Municipais, p. 76-80. EdUema.

Brito, E. P., Soares, J. F., Gomes, J. C., Borges, L. G., Vidigal, P. R. (2019). Interação e mediação na tutoria on line: a mensagem como canal dialógico. Revista Acadêmica Faculdade Progresso 5 (2), 2-14, http://revista.progressoead.com.br/index.php/academico/article/view/124/103. Acesso em: 04 jun. 2020.

Chassot, A. (2003). Alfabetização científica: uma possibilidade para a inclusão social. Revista Brasileira de Educação, 22, 89-100, https://doi.org/10.1590/S141324782003000100009. Acesso em: 04 jun. 2020.

Fundo das Nações Unidas para a Infância - UNICEF. (2020). Comunicado a Imprensa: Covid-19 - Mais de 95\% das crianças estão fora da escola na América Latina e no Caribe, estima o UNICEF. Panamá.

Gerhardt, T. E. and Silveira, D. T. (2009). Métodos de Pesquisa. Coordenado pela Universidade Aberta do Brasil - UAB/UFRGS e SEAD/UFRGS. Porto Alegre: Editora da UFRGS.

Luz, L. (2013). Mulheres e EAD: uma análise de gênero sobre o perfil dos (as) acadêmicos (as) na educação a distância no Brasil. Maiêutica-Serviço Social, 1(1), 95-100, https://publicacao.uniasselvi.com.br/index.php/SES_EaD/article/view/607, Junho. Acesso em: 05 jun. 2020.

Mesquita, N. A. S., Soares, M. H. F. B. Visões de Ciências em desenhos animados: Uma alternativa para o debate sobre a construção do conhecimento cientifico em sala de aula. Ciência \& Educação, v. 14, n. 3, p. 417-29, 2008.

Oliveira, F. A., Dos Santos, A. M. S. (2020). Construção do Conhecimento na Educação a Distância: Descortinando as Potencialidades da EaD no Brasil. EaD em Foco, 10, e799.

Paixão, G. C., Henriques, A. C. P. T., Pantoja, L. D. M., Vidal, E. M. (2016). Ingressantes em um curso de ciências biológicas a distância e a aprendizagem 
autorregulada. InFor - Inovação e Formação, Rev. NEaD-Unesp, São Paulo, 2(1), 249-265.

Pimentel, F. S. C., Lima, W. M., Silva Junior, L. C., Ferreira, A. R., Assunção, I. P. (2020). Atividades na pós-graduação utilizando as ferramentas digitais no contexto da crise da covid 19: análise qualitativa descritiva. EmRede, 7 (1), 276-293.

Ribeiro, R. T. M., Soares, L. K. B., Lobo, F. S. B., Pacheco, J. F., Pereira, V. A., Mendes, R. M. S., Pantoja, L. D. M., Paixão, G. C. (2018). Percepção Inicial dos Discentes de Um Curso de Ciências Biológicas a Distância: Possibilidades e Dificuldades. In: III Congresso sobre Tecnologias na Educação (Ctrl+E), Fortaleza, p. 192-203.

Santos Junior, V. B., Monteiro, J. C. S. (2020). Educação e Covid-19: as tecnologias digitais mediando a aprendizagem em tempos de pandemia. Revista Encantar Educação, Cultura e Sociedade, Bom Jesus da Lapa, 2, 1-15.

Silva, A. J. H. da. (2014). Metodologia de pesquisa: conceitos gerais. Guarapuava: Editora UNICENTRO.

Sousa Júnior, J. H., Raasch, M., Soares, J. C., Ribeiro, L. V. H. A. S. (2020). Da Desinformação ao Caos: uma análise das Fake News frente à pandemia do Coronavírus (COVID-19) no Brasil. Cadernos de Prospecção, Salvador, 13 (2), 331346.

Tamariz, A. D. R., De Souza, M. (2015). Educação a Distância no Brasil: perspectivas para redução na evasão de alunos matriculados. Linkania, 5(1), 227-253, http://linkania.org/master/article/view/330/199. Acesso em: 05 jun. 2020.

Vilaça, M.L.C. (2010). Educação a Distância e Tecnologias: conceitos, termos e um pouco de história. Revista Magistro, Rio de Janeiro, 1 (2), 2010, 89-101, http://publicacoes.unigranrio.edu.br/index.php/magistro/article/view/1197/801. Acesso em: 05 jun. 2020.

Xavier, T. B., Barbosa, G. M., Meira, C. L. S., Conte Neto, N.; Pontes, H. A. R. Utilização de Recursos Web na educação em Odontologia durante Pandemia COVID-19. Brazilian Journal of Health Review (BJHR), Curitiba, 3 (3), 4989-5000, http://www.brazilianjournals.com/index.php/BJHR/article/view/10525/8790. Acesso em: 05 jun. 2020. 